\title{
Modeling and Control Unmanned Surface Vehicle (USV) with Hybrid Drivetrain
}

\author{
Muhammad Arieb Salam, Rusdhianto Effendie AK., Nurlita Gamayanti* \\ Department of Electrical Engineering \\ Institut Teknologi Sepuluh Nopember (ITS) \\ Surabaya, Indonesia \\ *corresponding author : nurlitagamayanti@gmail.com, lita@ee.its.ac.id
}

\begin{abstract}
With the rapid development of unmanned surface vehicle (USV), the development of hybrid electric vehicles on USV is a technology that has a very important role to overcome the problem of how long the vehicle can be used. In hybrid electric vehicles (HEV), the main components consist of generators, electric motors, and batteries. Modeling component is intended to design models that fit on unmanned surface vehicle and represent the state of USV with hybrid drivetrain. This paper focuses on modeling USV with hybrid drivetrain. The major findings of this paper are the model of DC generator and DC electric motor that are related to the model of USV especially in energy generation and drivetrain. This vehicle uses a series configuration so that the generator act as a power generating system. The power system on USV was chosen using hybrid sources of DC generator and lithium-ion battery pack. The optimal size of DC generator and battery pack are very important to ensure that USV can work for a long period of time. This paper describes the simple characteristics of a DC generator with a PI controller and gain-scheduling PI controller which is accurate in generating $380 \mathrm{~V}$ output voltage according to the initial plan to be built. We also described the model of permanent magnet dc motor as a driver in USV and described simulation about 200Ah 36V lithium-ion batteries. The model that has been built in this paper ensures the detail and accurate with the desired design which are generator output voltage of $380 \mathrm{~V}$ and USV's speed of $314 \mathrm{rad} / \mathrm{s}$ and also $36 \mathrm{~km} / \mathrm{h}$ for linear velocity. The development of this model will be represented in MATLAB/Simulink.
\end{abstract}

Keywords-Unmanned Surface Vehicle, Hybrid Electric Vehicle, hybrid drivetrain, period of time.

\section{INTRODUCTION}

Nowadays, USV or an unmanned ship is very rapidly developing in industrial, military and scientific research. Unmanned surface vehicles are designed as an intelligent platform, which can operate in a marine environment with varying capabilities, one of which can operate fully automatically without operator monitoring and can perform various task previously given [1] [2]. The obstacle that is often encountered on USV is the time of their use which cannot last long.

Hybrid electric vehicles are technologies that utilize a combination of two engines which are internal combustion engines (ICE) and an electric motor. For USV, the configuration used in series to create a combination of power sources which are generator and battery. Batteries are used to provide power at low speeds or in silent mode. This hybrid technology combines electric power from a conventional vehicle engine and battery on an electric vehicle. Hybrid electric vehicles will convert energy into electricity when generators generate energy that is greater than the energy needed to drive an electric motor or when the battery is not fully charged. This electrical energy will be stored on the battery pack.
Several studies have presented modeling and simulation of hybrid electric vehicles [3-6]. Moudrik, Carlo, Gaolin and Dianguo modeled engines and electric engines in hybrid cars that use parallel-series configurations and rely on optimal models and controls [3]. Margaret, Sonya, Berhan, and Chris modeled a hybrid series electric configuration vehicle that fits into a hybrid electric from the High Mobility Multipurpose Wheeled Vehicle (HMMWV) using Ansoft SimplorerTM software [4]. Shanmuganathan, Govarthanan, Muthumailvaganan, and Imayakumar modeled the dynamic behavior of the IC Engine Permanent Magnet generator used in hybrid tracked vehicle [5]. Muhammad, Khandakar and Al Mahmudur modeled the motion system of permanent magnet synchronous motor in Simulink used in hybrid electric vehicles with the components are a generator, electric motor, photovoltaic cell and battery [6].

This paper focuses on simulating hybrid electric vehicles in series configuration by modeling generators using PID controllers and PID gain-scheduling controllers, electric motor models and simulating lithium-ion battery as energy storage system. The electric motor will be given the parameters of the ship to get the linear velocity of the ship as the response that wants to observe.

\section{MAthematical Modeling}

The dynamic model of a hybrid electric system on unmanned surface vehicle consists of a DC electric motor as its drivetrain, a generator as a power generating system and a battery for storing electrical energy [7]. Fig. 1 shows an overview of hybrid electric systems on USV with series configuration. This paper outlines the modeling of DC electric motor, modeling and controlling generator and lithium-ion battery models

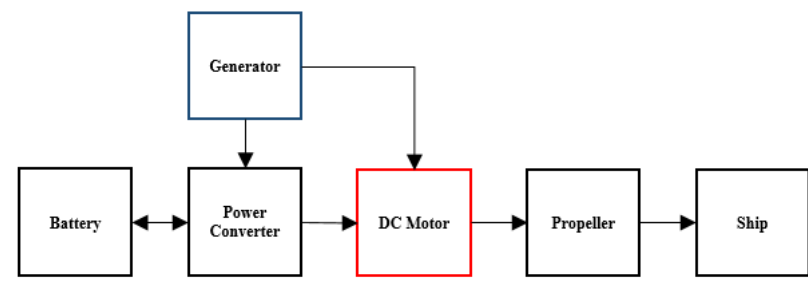

Fig. 1. Overview Unmanned Surface Vehicle with hybrid Drivetrain System

\section{A. DC Electric Motor}

The mathematical model of a permanent magnet DC electric motor will be described in [8]. Modeling is done by modeled the electrical and mechanical parts of the DC electric motor and the relationship between the two of them. When the voltage is applied to the coil, it will produce a torque on the armature. The torque on the motor $\left(T_{m}\right)$ is related to the armature current $\left(I_{a}\right)$ and the motor torque constant $\left(K_{t}\right)$ as in equation (1). 


$$
T_{m}=K_{t} * I_{a}
$$

The back electromotive force in the form of EMF voltage $\left(e_{a}\right)$ is generated due to the rotation of the armature windings in a fixed magnetic field. Equation (2) describes the generation of EMF voltages.

$$
e_{a}(t)=K_{b} \frac{d \theta_{m}(t)}{d t}=K_{b} \omega_{m}
$$

The electrical characteristics of DC electric motor can be explained by equations (3-4) below:

$\left(L_{a} s+R_{a}\right) I_{a}(s)=V_{\text {in }}(s)-K_{b} \omega_{m}(s)$

$I_{a}(s)=\left(V_{\text {in }}(s)-K_{b} \omega_{m}(s)\right) *\left(\frac{1}{L_{a} s+R_{a}}\right)$

Where the armature current is obtained from the input voltage minus the EMF voltage and multiplied by the electrical load of DC electric motor.

The torque generated by the motor will produce a rotational speed $\left(\omega_{m}\right)$ according to $J$ inertia load and damper friction $b$ of the motor. Equations (5-7) explain how the motor rotational speed is generated.

$K_{t} * I_{a}-T_{\text {Load }}-J_{m}\left(\frac{d^{2} \theta}{d t^{2}}\right)-b_{m}\left(\frac{d \theta}{d t}\right)=0$

$K_{t} I_{a}(s)-T_{\text {Load }}=\left(J_{m} s+b_{m}\right) \omega_{m}(s)$

$\omega_{m}(s)=\left(K_{t} I_{a}(s)-T_{\text {load }}\right) *\left(\frac{1}{J_{m} s+b_{m}}\right)$

The total of torque in a DC electric motor is equal to zero. Motor rotational speed is obtained from the relationship of motor torque, load torque, inertia, and damper friction.

The linear speed of USV is generated by the thrust of the vehicle. The thrust of the vehicle is obtained from the motor rotational speed and propeller constant. Equation (8) explains the relationship between vehicle thrust and motor rotational speed.

$F_{\text {thrust }}=\omega_{m} * K_{\text {prop }}$

The thrust on the vehicle will produce a linear velocity of the vehicle by the relationship of force and load of the vehicle as in the equation (9).

$v=F_{\text {thrust }} *\left(\frac{1}{m s+b}\right)$
JAREE-Journal on Advance Research in Electrical Engineering Volume3, Number 2, October 2019

Load torque $\left(T_{\text {load }}\right)$ will be obtained as a result of the linear speed of USV. Load torque reduces motor torque. Equation (10) describes load torque.

$T_{\text {Load }}(s)=(m s+b) * \frac{1}{K_{\text {prop }}} * v(s)$

\section{B. Generator}

The mathematical model of generators with energy generation derived from the internal combustion engine (ICE) is the main model of energy generation systems in USV with hybrid drivetrain system [9]. Modeling is done by modeled the rotating parts and also parts that produce field currents. The DC generator produces an electric voltage that comes from the relationship between generator angular velocity $\left(\omega_{r}\right)$ and field currents $\left(I_{f}\right)$. Equations (11-14) explain the relationship between them. Fig. 2 shows the DC generator diagram block.

$$
\begin{aligned}
& E_{g g l}=K_{g} \omega_{r} \varphi \\
& \varphi=B A \\
& B=\frac{\mu_{b} N I_{f}}{2 \pi l} \\
& \varphi=\frac{\mu_{b} N A I_{f}}{2 \pi l}
\end{aligned}
$$

The generator emf voltage $\left(E_{g g l}\right)$ is generated due to the relationship between generator's angular velocity and magnetic flux and also the generator constant. Flux density can be simplified like equation (14) of equation (13).

Generator voltage $\left(E_{g}\right)$ is generated by reducing the emf voltage with the load voltage $\left(E_{L}\right) . K_{g g l}$ and $I_{f}$ are simplifications of $K_{g}$ and flux in equation (11). Equations (1522) explain how generator voltage can be generated.

$$
\begin{aligned}
& T_{\text {shaft }}(s)=\left(\frac{K_{e} \tau_{d} s}{\tau s+1}\right) * \text { Throttle } \\
& \omega_{r}(s)=\left(\frac{1}{J s+B_{m}}\right) *\left(T_{\text {shaft }}(s)-T_{L}(s)\right) \\
& T_{L}=K_{T L} * I_{a r} \\
& E_{f}(s)=K_{A C} * \text { Control Signal } \\
& I_{f}(s)=\left(\frac{1}{L_{f} s+R_{f}}\right) * E_{f}(s) \\
& I_{a r}(s)=\left(\frac{1}{Z_{L}(s)}\right) * E_{L}(s) \\
& E_{g g l}=K_{g g l} * \omega_{r} * I_{f}
\end{aligned}
$$

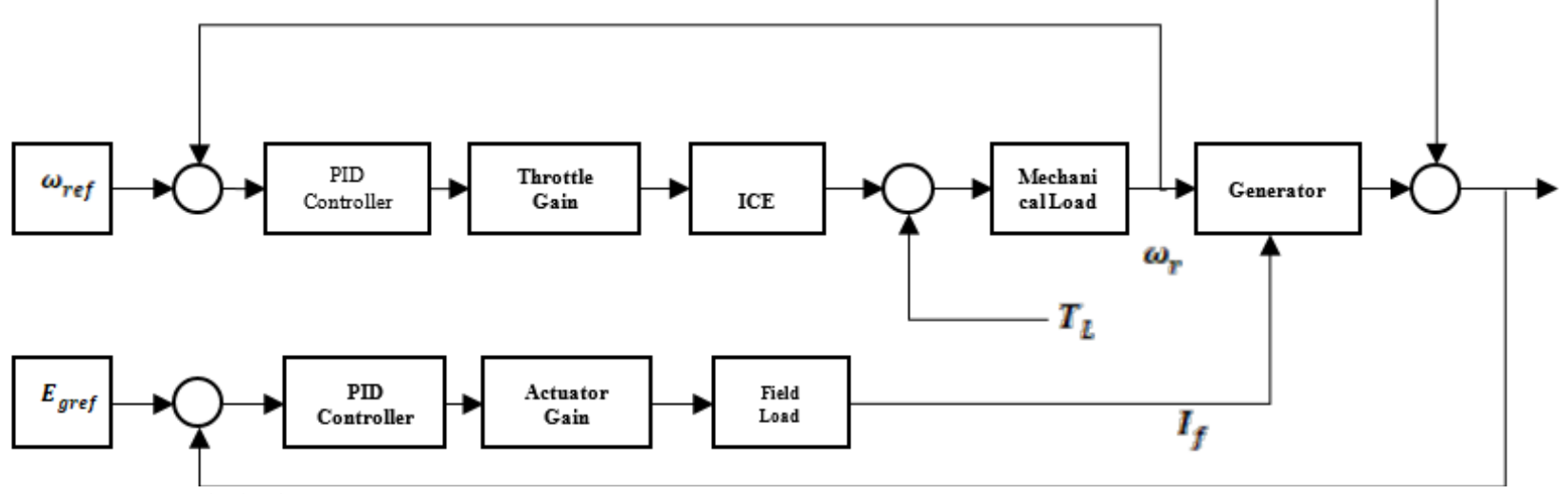

Fig. 2. DC Generator Block Diagram 


$$
E_{g}=E_{g g l}-E_{L}
$$

\section{Lithium-Ion Battery}

In the energy storage system, the battery is the main component in the system. A lithium-ion battery is one of the batteries that can be recharged. The use of lithium-ion battery is based on the development of this type of battery in hybrid electric vehicles. The advantage of this type of battery is it can store large power with a relatively smaller volume than other types of batteries while the disadvantage is expensive prices. In the future, the use of lithium-ion batteries will be very widely used from various types of electronic devices.

The energy will be stored on this battery when the generator excess energy from the amount given to the motor. The stored energy will be used on an electric motor when in stealth mode. Fig. 3 is a circuit of lithium-ion batteries simulation on USV with hybrid drivetrain.

\section{TABLE 1. BATTERY SPESIFICATION}

\begin{tabular}{|l|l|}
\hline \multicolumn{2}{|l|}{ Battery Type Lithium-Ion } \\
\hline Parameter & Value \\
\hline Full-Charge Voltage & $36.0836 \mathrm{~V}$ \\
\hline Capacity & $200 \mathrm{Ah}$ \\
\hline Cut-Off Voltage & $23.25 \mathrm{~V}$ \\
\hline Nominal Voltage & $31 \mathrm{~V}$ \\
\hline Capacity when Nominal Voltage & $180.8696 \mathrm{Ah}$ \\
\hline
\end{tabular}

Volume3, Number 2, October 2019

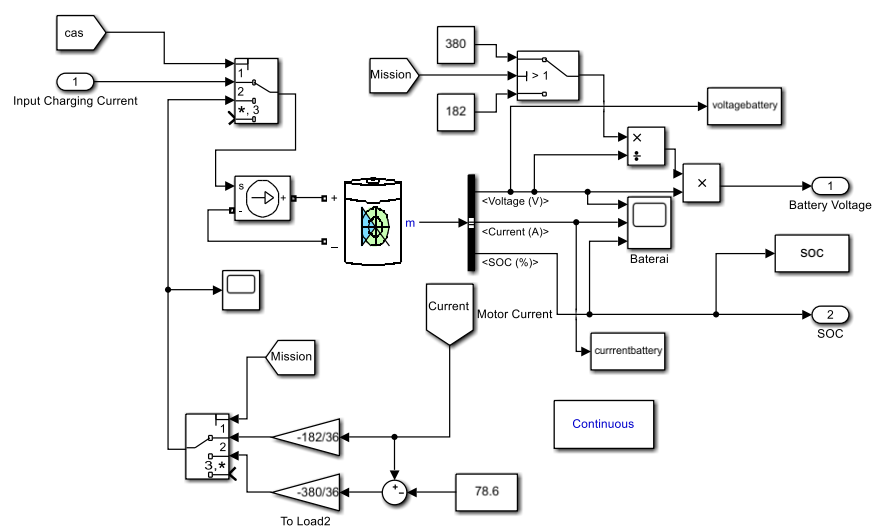

Fig. 3. Simulation circuit of Lithium-ion battery

Detailed specifications regarding lithium-ion batteries used are as in Table 1 .

The Simulink model of lithium-ion battery simulation consists of a lithium-ion battery model of specialized power systems and circuits for charging or discharging the battery according to the load.

\section{Overall System Design}

USV with hybrid drivetrain system combines simulation models of DC electric motors, generator, and lithium-ion batteries. Fig. 4 shows a simulation model of the Overall system that has been designed

\section{SimUlation StUdiES AND RESUlt}

\section{A. DC Electric Motor}

Simulations are carried out on each sub-system that has been modeled and made before.

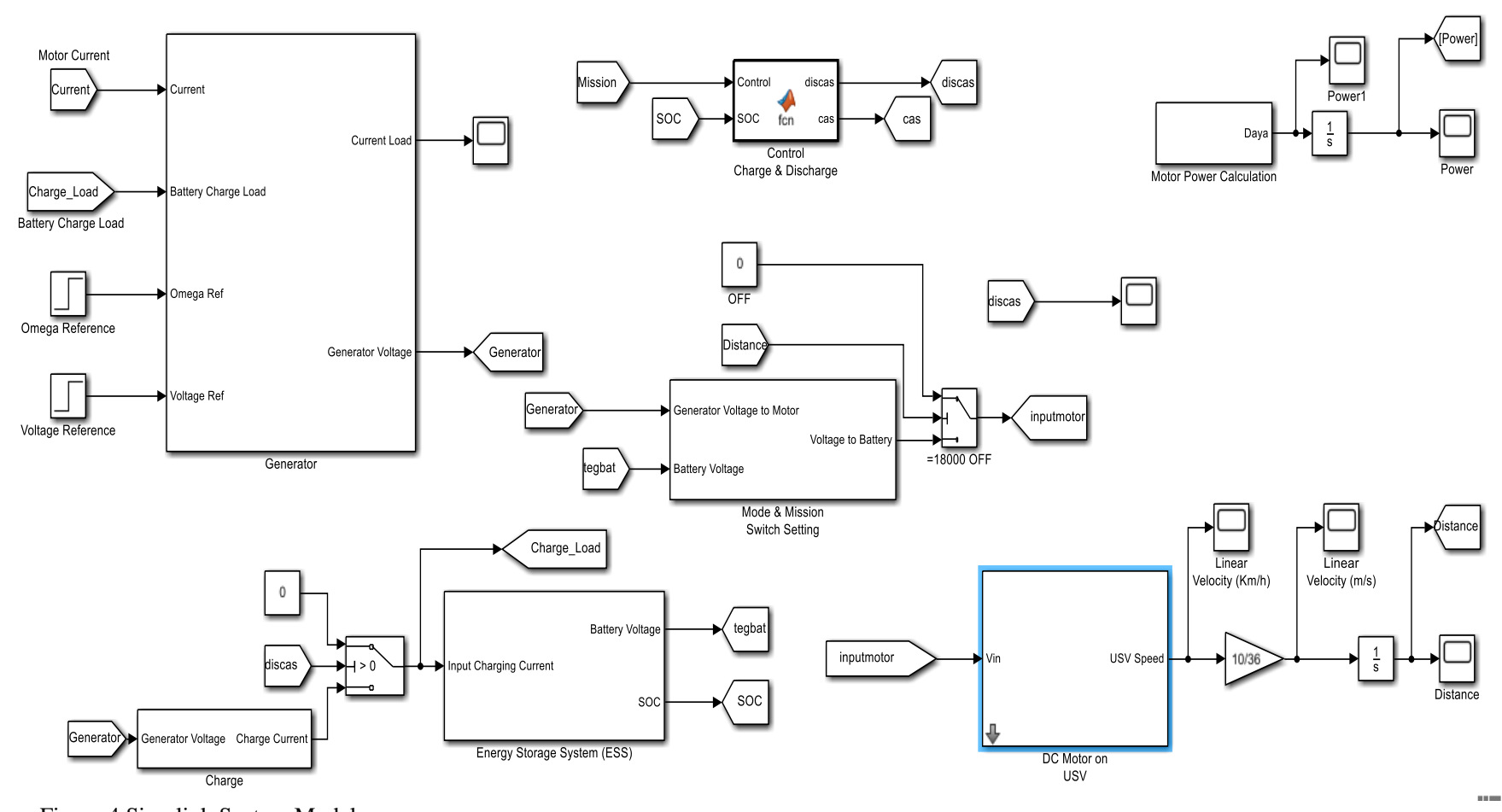

Figure 4 Simulink System Model 
JAREE-Journal on Advance Research in Electrical Engineering

Volume3, Number 2, October 2019

In a DC electric motor, the desired motor angular velocity are $314 \mathrm{rad} / \mathrm{s}$ and linear velocity $36 \mathrm{~km} / \mathrm{h}$ with the input voltage is $380 \mathrm{~V}$. However, when the motor is supplied from the generator, the input voltage drops so that motor speed decreases. To overcome this problem, an energy source from the battery will be added to reach a voltage of $380 \mathrm{~V}$. Fig. 5 shows the result of motor angular velocity when given the generator input. From these results, the motor input voltage is only $270 \mathrm{~V}$ which means it still less than the desired voltage. This happens because the generator has a voltage drop due to the generator load that is greater than the load it can hold.
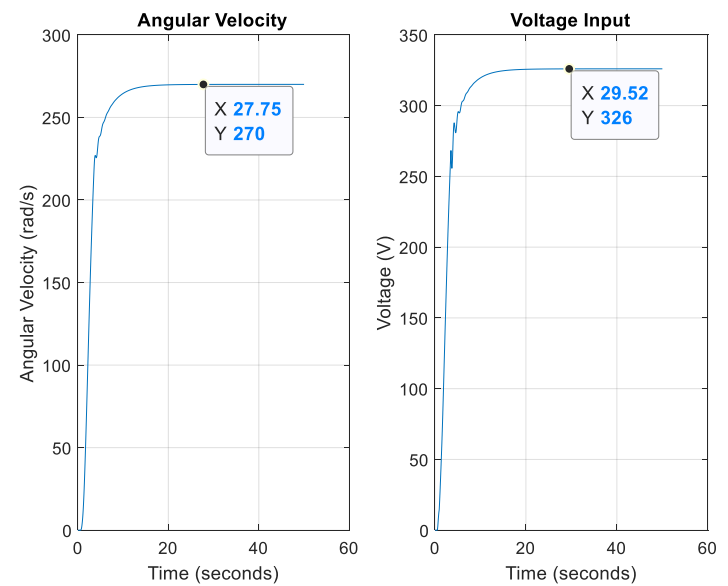

Fig. 5. Angular Velocity from Generator source

To reach a voltage of $380 \mathrm{~V}$, an additional source is needed from the battery. The battery will supply energy so that the voltage input is $380 \mathrm{~V}$. Fig. 6 is the result of the motor angular velocity.
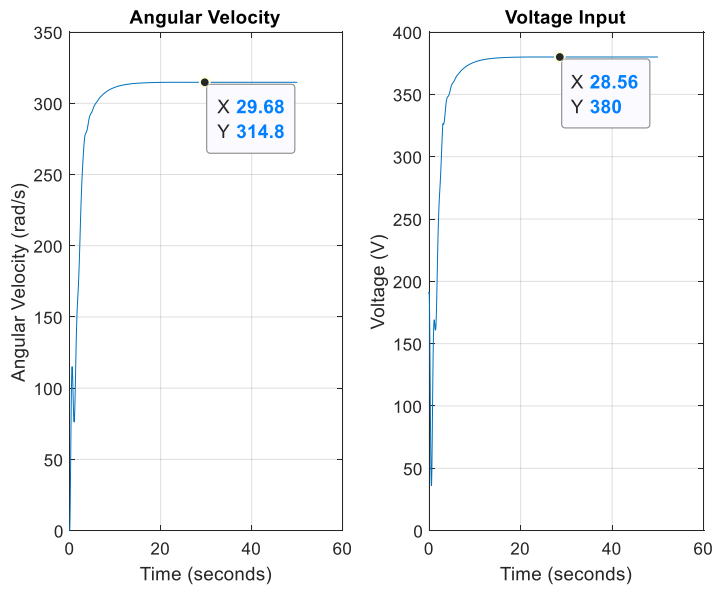

Fig. 6. Angular Velocity from $380 \mathrm{~V}$ source

The results of a linear velocity of USV with $380 \mathrm{~V}$ input voltage will be shown in Fig. 7. The speed $36 \mathrm{~km} / \mathrm{h}$ has been reached as the desired design.

\section{B. Generator}

The generator dynamic model will be simulated to observe the output voltage response, the angular velocity of generator $314 \mathrm{rad} / \mathrm{s}$ and field current $9.744 \mathrm{~A}$ for no load applied. While the load is applied, the voltage output will decrease. To increase the voltage, the controller in the field is needed so that the field current value increases to $380 \mathrm{~V}$.

In the rotor part, the generator angular velocity is maintained at a value $314 \mathrm{rad} / \mathrm{s}$. With the mechanical load in the generator, a PID controller is needed to maintain its value. Fig. 8 shows the generator angular velocity response.
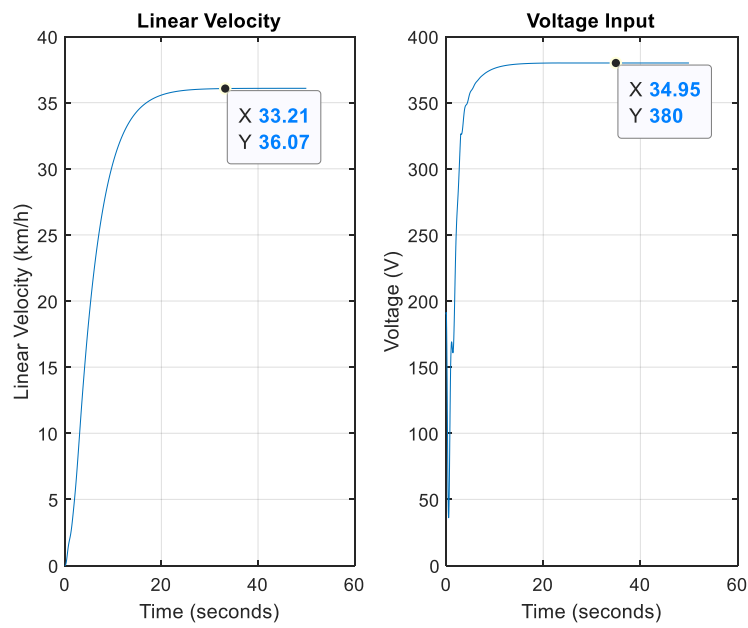

Fig. 7. Linear Velocity from $380 \mathrm{~V}$ source

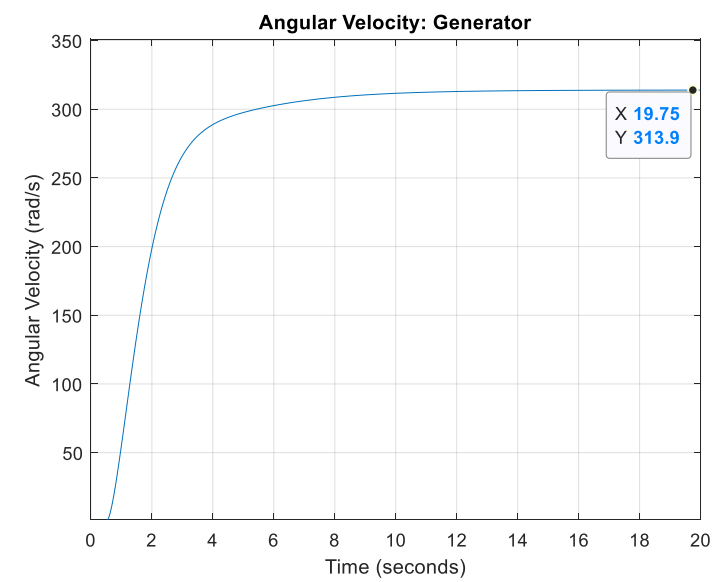

Fig. 8. Angular Velocity of Generator

The generator field will maintain the output voltage. When the generator load increases, the field current will rise following the load received. Fig. 9 shows the result of the field current and output voltage when no load applied and Fig. 10 shows the result with a load of $50 \mathrm{~A}$.
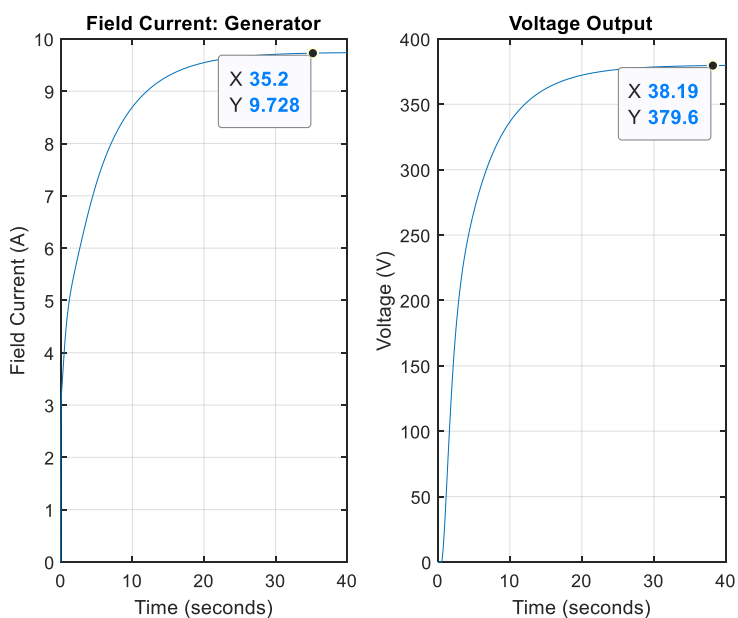

Fig. 9. Field Current and Output Voltage (No Load) 
JAREE-Journal on Advance Research in Electrical Engineering

Volume3, Number 2, October 2019
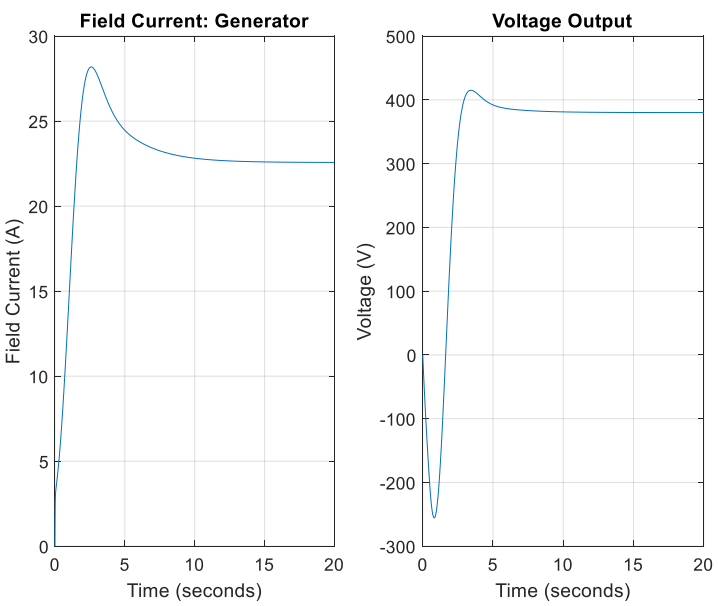

Fig. 10. Field Current and Output Voltage (50A Load)

\section{Lithium-Ion Battery}

Lithium-ion batteries simulation is done by providing charging and discharging current on the battery. The specifications of the battery are mentioned in Table 1 before. The response that is noticed in this lithium-ion battery are the state of charge (SOC), battery voltage and current. If the battery current is negative, it means that the battery is charged. Fig. 11 shows the result of the lithium-ion battery response.

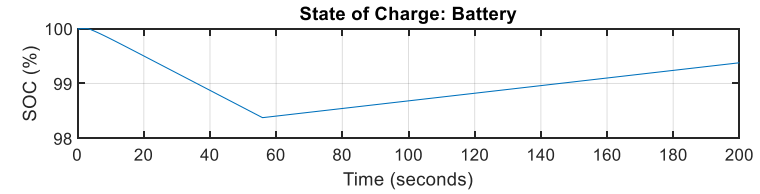

Battery Current
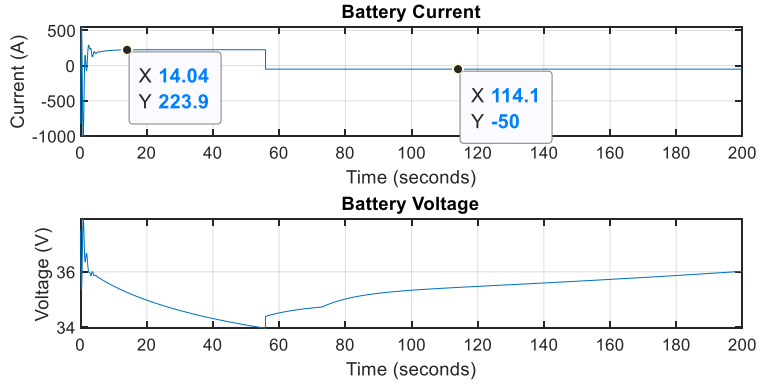

Fig. 11. Performance overview lithium-ion battery

The figure shows that the battery will discharge 223.9A at $0-58 \mathrm{~s}$ which will reduce the battery's state of charge and voltage according to the needs of the electric motor. While the battery is not fully charged, the battery will be charged by the generator if the generator supplies electric motor. From the fig. 11 at $59^{\text {th }}$ second, the battery starts to be charged with $50 \mathrm{~A}$ current in order to increase the SOC and voltage of battery.

\section{Overall Performance Result}

Fig. 12 represents an overall result of unmanned surface vehicle hybrid power system with series configuration. Here the angular velocity and linear velocity of DC motor from the source of battery, generator + battery, and generator respectively. The vehicle will do stealth mode while using the battery as a source and also in low-speed mode which the speeds are $150.7 \mathrm{rad} / \mathrm{s}$ and $17.28 \mathrm{~km} / \mathrm{h}$. The vehicle will do full-speed mode if the sources are from battery and generator that are $314 \mathrm{rad} / \mathrm{s}$ and $36 \mathrm{~km} / \mathrm{h}$. As the source from the

generator, the vehicle will do nominal speed mode with angular velocity $260 \mathrm{rad} / \mathrm{s}$ and linear velocity $29.8 \mathrm{~km} / \mathrm{h}$.

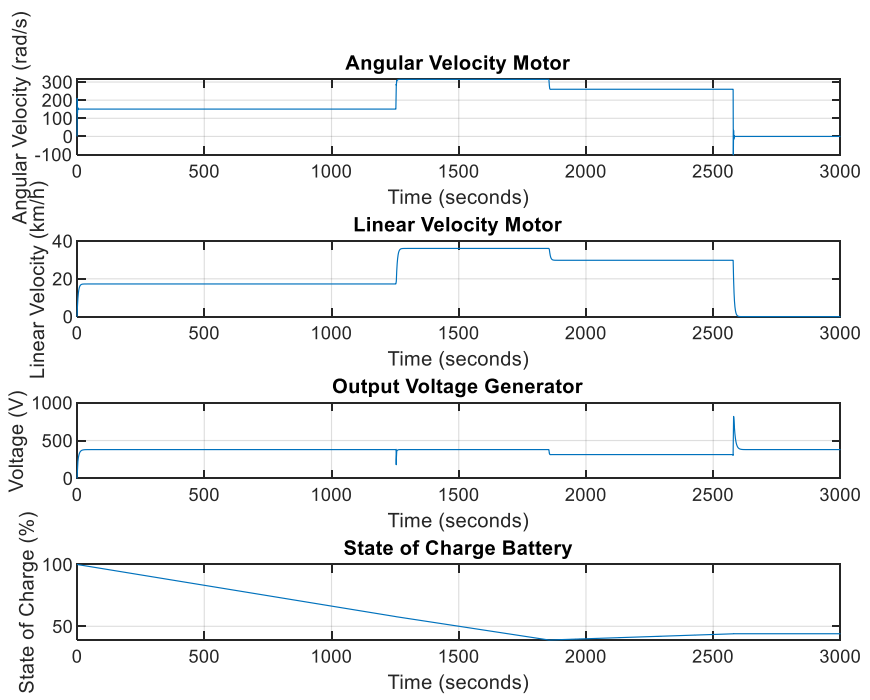

Fig. 12. Overall Performance Result

The voltage output generator is $380 \mathrm{~V}$ while no load applied on it. If the generator is supplying energy to DC motor, the load will increase due to load from DC motor and will decrease the voltage output generator to $314 \mathrm{~V}$. In full-speed mode, the deficit of energy will be supplied from the battery to return to $380 \mathrm{~V}$ input for $\mathrm{DC}$ motor.

From the $4^{\text {th }}$ figure in Fig. 12 shows that state of charge battery decreases together with the use of its energy to DC motor. In nominal speed mode, while the source of the motor is just from the generator, the battery will be charging. From the results, output performance result clearly satisfying as the responses are appropriate with the desired design.

\section{CONCLUSION}

In this paper mainly discussed modeling, control and, simulation of Unmanned Surface Vehicle with hybrid drivetrain. More specifically modeling the components of USV such as DC motor, generator and, lithium-ion battery. Each response from the components is observed and analyzed. A comparison of the performance of various components with the desired design is done. The growth of unmanned surface vehicle (USV) technology is rapid and also the technology of the hybrid electric vehicle. The difficulty that usually shows in USV is about the long-lasting duration of use. That means the long-lasting vehicle is largely dependent on the sustainability and flexibility of its power system. Besides this major advantages of USV with hybrid drivetrain are the lower emission of $\mathrm{CO}_{2}$ which ensures the safety of environment and economically can save even more due to high price of the fuel in the market. This paper represented a complete Simulink model of USV with hybrid drivetrain which driver are internal combustion engine as power generating system and DC motor as driver of vehicle and the vehicle is powered by generator and Lithium-ion battery.

The model represented in this paper ensures the detail and accurate with the desired design. The generator is designed to generate output voltage $380 \mathrm{~V}$ with no load and DC motor is designed to drive the vehicle with speed $314 \mathrm{rad} / \mathrm{s}$ as angular 
JAREE-Journal on Advance Research in Electrical Engineering Volume3, Number 2, October 2019

velocity and $36 \mathrm{~km} / \mathrm{h}$ as linear velocity with input voltage 380 V. This simulation is done with MATLAB Simulink. The Hybrid drivetrain in Unmanned Surface Vehicle can play the key role to improve the efficiency of this model and also the sustainability of the vehicle.

\section{ACKNOWLEDGMENT}

The authors would like to acknowledge the Advisor and member of System and Cybernetic Laboratory AJ-204 and also continuous support from Electrical Engineering Department especially control system.

\section{REFERENCES}

[1] Department of The Navy United States of America, "THE NAVY UNMANNED SURFACE VEHICLE (USV) MASTER PLAN," 23 July $2007 . \quad$ [Online]. Available: https://www.navy.mil/navydata/technology/usvmppr.pdf. [Accessed 6 February 2019].

[2] Y. Du, J. Gao, L. Yu, J. Song, F. Zhao and W. Zhan, "HEV System Based on Electric Variable Transmission," in IEEE Vehicle Power and Propulsion Conference, Beijing, 2009.

[3] M. Meradji, C. Cecati, G. Wang and D. Xu, "Dynamic Modeling and Optimal Control for Hybrid Electric Vehicle Drivetrain," in IEEE International Conference on Industrial Technology (ICIT), Taipei, Taiwan, 2016.

[4] M. Ducusin, S. Gargies, B. Berhanu and C. Mi, "Modeling of Series Hybrid Electric High Mobility Multipurpose Wheeled Vehicle," in IEEE Vehicle Power and Propulsion Conference, Chicago, USA, 2005.

[5] U. Shanmuganatan, R. Govarthanan, A. Muthumailvaganan and A. Imayakumar, "Modeling and Dynamic Simulation of IC Engine Driven Permanent Magnet Generator Using Matlab/Simulink for
Hybrid Tracked Vehicle," in IEEE Conference on Electric and Hybrid Vehicle, Pune, India, 2006.

[6] M. S. A. Chowdury, A. M. Rahman and K. A. Al Mamun, "Modeling and Simulation of Power System of Battery, Solar and Fuel Cell Powered Hybrid Electric Vehicle," in 3rd International Conference on Electrical Engineering and Information Communication, Dhaka, Bangladesh, 2016.

[7] T. v. Keulen, B. d. Jager, J. Kessels and M. Steinbuch, "Energy Management in Hybrid Electric Vehicles: Benefit of Prediction," in International Federation of Automatic Control (IFAC) Symposium Advances in Automotive Control, Munich, 2010.

[8] A. A. Mahfouz, M. M. K. and F. A. Salem, "Modeling, Simulation and Dynamics AnalysisIssues of Electric Motor, for MechatronicsApplications, Using Different Approaches andVerification by MATLAB/SIMULINK," International Journal , vol. 5, no. 5, pp. 39-57, 2013.

[9] K. J. Astroom and R. M. Murray, Feedback Systems: An Introduction for Scientists and Engineers, Princeton University Press, 2010.

[10] W. K. Chen, The Electrical Engineering Handbook, Academic Press, 2004.

[11] P. Singh and A. Nallanchakravarthula, "Fuzzy Logic Modelling of Unmanned Surface Vehicle (USV) Hybrid Power System," in Intelligent Systems Applications to Power Systems (ISAP), Arlington, 2005

[12] Liu, Zhixiang; Zhang, Youmin; Yu, Xiang; Yuan, Chi, "Unmanned Surface Vehcle: An Overview of Developments and Challenges," Annual Reviews, Montreal, Canada, 2019.

[13] D. Pal, "An Introduction to DC Generator Using MATLAB/SIMULINK," Imperial Journal of Interdisciplinary Research, vol. 2, no. 4, pp. 935-938, 2016.

[14] B. Zhonghao and W. Yaonan, "Research on Modeling and Simulation of Hybrid Electric Vehicle Energy Control Systems," in International Conference on Electrical Machines and Systems, Nanjing, China, 2005. 